\title{
Environmental Operations Review and Stakeholders' Wealth of Extracting Firms: Evidence From Nigeria
}

\author{
Akabom Ita Asuquo ${ }^{1}$, Nicholas Obun Dan ${ }^{1}$, Innocent Oko Odey ${ }^{1}$, Mkpa Ubuo Linus $^{1}$, Ashishie Peter Uklala ${ }^{1} \&$ \\ Arzizeh Tiesieh Tapang ${ }^{2}$ \\ ${ }^{1}$ Department of Accounting, Faculty of Management Sciences, University of Calabar, Calabar, Cross River State, \\ Nigeria \\ ${ }^{2}$ Department of Accounting, College of Management Sciences, Michael Okpara University of Agriculture Umudike, \\ Abia State, Nigeria \\ Correspondence: Akabom Ita Asuquo, Department of Accounting, Faculty of Management Sciences, University of \\ Calabar, P.M.B. 1115, Calabar, Cross River State, Nigeria. Tel: 234-806-646-8333.
}

Received: November 1, 2020

Accepted: December 28, 2020

Online Published: January 20, 2021

doi:10.5430/ijfr.v12n3p172

URL: https://doi.org/10.5430/ijfr.v12n3p172

\begin{abstract}
The research surveyed environmental operations review and stakeholders' wealth of extracting firms taking evidence from Nigeria. The purpose was to consider the effect and necessities of environmental evaluation toward enhancement and maximization of the wealth of the stakeholders of extracting firms obtaining facts from Nigeria. The survey methodology and ex-post-facto design were adopted and material pieces of evidence needed for the validation of the propositions made in the exploration were gathered from both primary and secondary sources, and appropriate statistical techniques were applied in examining the raw material pieces of evidence. The domino effect and findings exposed that environmental operations review is greatly connected to the stakeholders' wealth in the extracting firms. Consequently, the elements of environmental operations review ought to be reflected in making a decision concerning stakeholders' wealth of extracting firms because it is appropriate that establishments put up with their stakeholders' wealth in the midst of environmental defies. Finally, as originality/value, it was advocated and backed that extracting firms ought to display facts on environmental costs in their financial statements. This is obligatory in ensuring that environmental overhead besides environmental conservation is guaranteed towards ecological and green nourishment and sustenance.
\end{abstract}

Keywords: environmental, extracting, firms, operations, review, stakeholders, wealth

\section{Introduction}

Brian (1999), Gray (2003), Greenwood (1999), Harrington (2000), Hohmeyer (1993) and Murphy (2003) averred that environmentally friendly matters used to be disregarded and thrown away frequently by the principal stakeholders of the environment. Dangerous and precarious inhospitable surroundings and rubbishes continued as indispensable misplaced of a developing frugality. But currently, the general publics has come to the knowledge and recognize the consequence of unwanted and discarded items and objects that possibly will ruin, destroy, and impair the surroundings and environs. Moreover, individuals presently know that conserving and stabilizing olive green midair, water and land is so imperative and essential compare to lesser price tag manufactured goods meant for users or great and extraordinary yields and earnings for commercial corporations. It should be pointed out that a lot of individuals remain prepared to buy and consume merchandise and products which are ecologically and naturally pleasant and satisfying. Extremely, the dispute and run-in are that people who own the environs together with the extracting firms that are inhabitants in the environs obtained the degree of advantage and value as of the environs and ecosystem. Consequently, the inhabitants and beneficiaries of the ecosystem ought to make sure that the environment is secured and safe to permit maintainable and viable paybacks and welfares. Awasthi (2009) talked about the extended period of healthiness and fitness of the universal habitats besides justifiable and maintainable ecological development and subsidy intended to cater to the necessities of the contemporaneous devoid of meet halfway the capability of the upcoming compeers to run into their particular wants and necessities. Moreover, as averred by Asuquo (2012), there is specific need for organizations operating within the confined of the environment to establish and maintain environmental-friendly policies in order to sustain and safeguard the ecosystem and natural habitats. 
Besides, environmental impact assessment of global initiatives required continuous evaluation of the impact/effect of business activities on the environment and how these activities generate financial implications of the wealth of the various stakeholders (Asuquo, Dan \& Effiong, 2020).

Brian (1999), Effiong and Asuquo (2010), and Frank (2000) explained the unlimited necessity to understand and appreciate that the whole thing that happens in the environs and ecosystem has a fundamental charge, in addition to being the factor for realization and lack of realization of the set goals of the interested parties to the business, and consequently guarantee the survival of the business and business environment. Backman (2003) also expressed apprehension and fear about commercial and societal obligations as well as activities of firms which ought to have enlarged in addition to spawning arguments and debates in the midst of concerned persons through the effort of deciding the key obligation concerning performers in the business environs coupled with the social request and mandate.

Babbie (1990) pointed out the probable and normal starring responsibility of enterprises in relations to the business collective obligation which had presumed a fresh height through the main matter that centers on the thoughtfulness of the predominant and fundamental memo of appreciating the parceled flanked by the corporation plus the domicile municipal, the firm ought to be saddled by the extra obligation not hitherto demarcated. The dispute is strengthened due to the circumstance which commercial outfits remain progressively involve in extra concern in relations to safeguarding a healthier and improved surroundings/atmosphere in addition articulating and effecting publicly and more friendly leaning projects and schemes which proliferate the mesh subsidy and value of the abode societies despite the fact that the projected earnings are still made.

In the direction of evaluating the determinations of firms en route for the self-actualization of their obligation to the environs is the conservational and eco-friendly review, which this research work attempted to search by way of mechanism to highpoint provisional obligations emanating after ecological dilapidation. The general stress is on conservational and ecological safeguarding, plus the capability of the conservational and eco-friendly review and check to envisage legal responsibility for continuous undertakings and operations of the firms within the mutable environs. Cohen, Fink, Gadon, and Willits (2001), Davis and Okorite (2004) stressed that in spite of the enormous paybacks and profits firms received courtesy of the business environs within which they operate, they still do not see pressing needs of preserving the natural environs. Business firms disregard the consequences of many interfaces that occur amid them and the business environs thereby mortgaging the future well-being of the environment for the immediate gains. Business firms ought to understand that a favorable and contributing to collective environs and ecosystem certainly increase the viability and cost-effectiveness of their operations. It should also be ascertained at this introductory stage as pointed out by Asuquo (2012b) in his paper that, information technology and forensic accounting techniques/mechanism could be effectively and efficiently applied in the processes of environmental operation review, environmental impact assessment, and stakeholders' wealth ascertainment.

\section{Literature Review}

\subsection{Interest Parties of the Environments}

Eyre (1982) and Friedman (1980) pointed out that interested parties to the environments are numerous and must be reflected in the development and the materialization of business goals, intentions, and missions. The interested parties to the environment range generally to embrace both internal and external parties such as investors, directors, workforces, customers/buyers, providers as well as the domestic public. Furthermore, organization goals required the concern and benefits of all who is probably going to be affected by the commercial undertakings of the corporations when setting them. The stress and prominence are that welfares and benefits of the interested parties to the environment essentially ought to be considered at any of making a decision. Hence, a guiding principle and the program aimed at environmental and ecological preservations necessitate and facilitate the achievement of the organizational objective of stakeholders' wealth maximization, as this the ultimate objective of every business organization from inception.

Cohen, Fink, Gadon, and Willits (2001) and Repetto (1989) asserted the obligatory and indispensable need aimed at prompting firms in the direction of investigating their starring responsibilities and connection through the interested parties in cooperation of personages as well as the general public towards the sustenance of business environments. Moreover, this submission is in line with the environmental operations review policies and guidelines, aimed at locating hale and hearty margins and confines which boost and enrich active besides resourceful process. An efficacious putting into the practice of the initial strategy which should assist the executive in establishing goals which accomplish their identifiable concern and yield earnings that placate and soothe the proprietors. Each strategy aimed at the accomplishment of the stretched out objective of the establishments ought to and essentially integrate 
the wealth required to realize the conventional aim.

\subsection{Environmental Sustainability Notion}

Anijah (2001), Effiong and Asuquo (2010), Prestone (1992), IUC (1980), John (2001) and Repetto (1989) predicted and documented the fact that no high-quality exist concerning stabilizing and protecting the environment since one possibly will not ascertain the later short of the former. The matters of maintainable and supportable enlargement of the economy besides the environment are interconnected and frequently conjointly underpinning. Maintainable improvement is enlargement stratagem and the scheme that survives resources entirely, equally the regular and social assets for the good fortune of the public and businesses. Additionally, supportable and justifiable growth as a goal-line and aim discards strategies in addition to procedures which accept present industrial principles which exhausts and drains creation sources together with normal assets, before abandoning upcoming people using worse visions besides inordinate and unwarranted threat. Furthermore, as asserted by Asuquo (2012b) application of information technology and forensic mechanisms in the documentation of environmental resources, as well as stakeholders' wealth, could enhance environmental sustainability perception.

Asuquo (2012a), Awasthi (2009), and Repetto (1989) maintained that growth and expansion are essential social moral values and harmony which forms the foundation for improvement on the foundation of environmental maintainability for the future well-being of the populace. Similarly, the essential and ultimate degree is that the environs make available biotic, element, and corporeal structures that facilitate social and mortal existence. They further pointed out that it is in the environs that mortal acquires fresh resources plus dynamism for financial creation in addition to domestic undertakings; hence the environment needs to be preserved for the present and usages. Consequently, progress in communiqué that motivates increasing communal consciousness on eco-friendly as well as societal matter must be stressed and developed.

Koutsoyiannis (2003) and Olugbile (1987) drew dissimilarity flanked by interior cost-cutting of gauge besides exterior frugality of gauge. Exterior frugality ascends outer the corporation for the upgrading of the environs in that the corporation functions. At this time, shared intelligence commands the environs lay open to using starved of processes for the aforementioned enhancement, thus causing it to depreciate. Conceivable consequential could be upsurges in the price of creation since the corporations do not at all revel in exterior financial benefit. Copious exertions plus funds are being positioned to make sure that investors take safeguarding networks as a major factor of production without which no meaningful productive activities could take place or investment will be unyielding. What is more, the reorganization procedures comprising denationalization ought to be applied preemptively to augment conservational continuity. Moreover, as suggested by Uwah and Asuquo (2016) capital budgeting processes could be used to promote the shareholders' wealth maximization objectives of the firms and consequently guaranteeing the conservation continuity.

\subsection{Price Value Principle}

The conservational price-value principle articulates that the price to carry out a project ought to be less value compared to the value receivable from the undertaking; otherwise, the project is not viable and should not be embarked on. This principle strives for investigating the price efficiency and usefulness of diverse options for the purpose of comparison of price and value derivable from the venture which the later must offset the former due to financial accounting standards and reporting practices of the business entities operating in the environment. Fashioning reasonable procedures of the prices in addition to the advantage of definite activities is normally so challenging. Basically, specialist attempts to approximate price as well as an advantage or whichever by means of review technique. Ecological and ecofriendly price-advantage principle tries to arrange significant and related conservational charges besides advantage collectively (Dawkins, 2003, Edwards, 2005, Frank, 2000, \& Hodges, 1973, Asuquo, 2013).

\subsection{Environmental Influence and Operations Review}

Ojile (1998) and Okon (2018) 'unpublished' stressed that environmental influence and operation review is a compulsory and an obligatory exercise which should be observed prior to every innovative and evolving scheme that is to be undertaken. Environmental influence review is demarcated as organized and efficient procedure concerning the documentation, safeguarding, estimation as well as a demonstration of the plausible as well as conceivable significances of a wished-for scheme, strategy or plans at a phase of the resolution creating wherever severe ecological injuries and harms could be evaded or curtailed. Globally, environmental schemes, objectives plus ideologies of environmental effect review, are well-defined as scrutiny, inspection, and review of premeditated undertakings by way of guaranteeing ecologically and naturally all-encompassing growth and enlargement. Factually, 
environmentally influence the review involves biotic, somatic in addition to the cost-effective mechanism of planned developing feat.

Gilpin (1995), Munasinghe (1993), Sada (1999), Raw and Jackson (2006) maintained that the pecuniary worth of existence in society could not be unremitting indeterminately if the plan resulted in hostile variations in the environs. Supportable growth would not be attained if the effect of plans on the environs has no thoughtful responsiveness. This entails the practice of recognizing the effect of the plans on the environment in order to ascertain whether the schemes exert an adverse effect on the environs and if this effect could be evaded thereby improving the usage of the environs in a way of providing for the necessity of the contemporaneous devoid of conceding the capability of the upcoming age group in meeting their own necessities. The procedure of environmental effect review has to be incorporated into the significant enlargement so as to touch the enlargement action to be scrutinized at the initial phase in the preparation of the scheme before resolutions concerning plan proposal as well as the site to be assured. Environmental effect and operation reviews are normally carried out in three phases. The phases ensure prior to the initiation of the schemes. The phases are: Preliminary examination, prompt environmental effect recognition and identification, and wide-ranging environmental effect and operations review (Rilwani \& Aziegbe, 2001).

\subsection{Current Cost Consequences of Environmental Undertakings and Operating Capabilities of Firms}

Innumerable undertakings are recognized stretching after commercial growth, operating capacities of firms and enlargement, deforestation, utilization of the ordinary wealth, leftover and refuse creation, greenhouse gasses, toxic waste, and many others. A cautious and guarded survey of these enumerated undertakings and human actions expose that these actions and events whether conceded unswervingly or incidentally, are meant to be useful to the business firms in ensuring operating capabilities and establishments as a consequence of incurring the current costs. Again, there is correlational and differential influence of historical cost and current cost profits on the operating capabilities of the firms operating in the environment (Effiong, Udoayang \& Asuquo, 2011).

Wright and Noe (2006) opined that conservational charge comprises of conservation procedures plus ecofriendly damages. These consist of sanitation fees, the charge of reconditioning resources, cessation price, resources outlay plus expansion expenses. Ecological and ecofriendly processes are the current cost suffered in averting, decreasing or refurbishing impairment to the environs and safeguarding assets. Conservational and ecofriendly damages are charges which convey losses to the business, for examples penalties, punishments charges, reparations as well as dumping charges, and termination fee. Torstein (2006) and Harrington (2000) detected that the actual plus inferred conservational charges connected eco-friendly and ecological security and shield are effortlessly the utmost hindrances to purer midair in addition to aquatic, upgraded conservation of environments in addition to ecological unit besides deliberate exhaustion of normal wealth.

Digo (2004), Smith (2003), Asuquo (2013) and Welford (1995) perceived the dare of conservational book-keeping, financial accounting standards and reporting practices and how they could affect the process of establishing innovative book-keeping technique meant for valuation of contamination regulatory procedures matching another possibility. It should be pointed out that the principal obstacle and bottleneck to the implementation of cleanser invention besides creation within the ecosystem to ascertain effectiveness and proficiency is that companies are ignorant of the conservational and ecological charge of running corporate entities as well as ignoring the economic value that could come due to decreasing conservational and ecological effects.

\section{Materials and Methodology}

\subsection{Research Design}

The research work embraced a survey alongside expo-facto research designs in order to collect facts to assist in verifying propositions articulated for the research work. The ex-post facto design was adopted in this study because it is an empirical systematic inquiry that does not give the investigators the ability to influence the independent variables since they are naturally not operated. At the time of the study, the environmental operations as well as conservation activities of the various firms had previously taken place. This design also helped the investigators to establish, designate and clarify existing phenomena and induce overview on the study universe established on the data gathered from the sampled firms for investigation. Furthermore, modern technological and statistical mechanisms were applied to collect and screen the data used (Asuquo, 2012b).

\subsection{Population and Sample Size}

The population for the survey is made up of ten extracting firms functioning in Nigeria. Then five extracting firms in the South-South region were carefully chosen to make up the sample size. The purposive sampling method was adopted as a result of inaccessibility to all the entities in the coverage area and lack of the required data in those 
entities. However, the approach ensured that representative firms were selected and adequate data were collected for the analysis.

\subsection{Instrumentation and Method of Facts Gathering}

Facts and measurements were engendered by the application of a well-thought-out and regulated inquiry form. A thirty item inquiry form was advanced to ascertain facts about the qualitative part of the main variables in the research. The information obtained from the inquiry form was screened and quantified for final analysis. Also, the financial records of the firms under review were scrutinized to gather the secondary aspect of the facts.

\subsection{The Validity of the Research Mechanism}

In order for the instrument used in this study to be considered valid, the data were extracted and presented to accounting experts to assess and evaluate. This helped in determining whether the extracted data actually measured what they were desired to measure. Moreover, since the data were dominated by secondary facts, they were unbiased.

\subsection{Reliability Test of the Research Mechanism}

To guarantee the test of the mechanism's reliability, the testing method of data and data structure adopted were taken to be reliable because they could be applied consistently in parallel exploration processes to produce expected results. The data collected were test screened to ensure the validity of the information obtained before the main examination was carried out.

\subsection{Limitations of the Study}

Coverage of the study population was constrained by inaccessibility and other interferences often faced by researchers. As such, only five of the relevant companies were selected using a purposive sampling technique. Another significant constraint was in the shortage of relevant material and statistical data. Unwillingness to divulge comprehensive facts and figures on environmental expenditures and operation review activities by workers of the chosen firms, who were the study respondents, also posed a serious impediment to the research work.

\subsection{Model Specification}

The model below was specified to capture the relevant variables needed to reveal the impact of the environmental activities undertaken by the various extractive firms under investigation, on the stakeholders' wealth. In the model, Stakeholders' wealth [SW] is the dependent variable and the environmental operation review [EOR] is the independent variable and was represented by Charges \& forfeits [CF], Interested parties' backing [IPB], Environmental safeguarding price tag [ESPT], Provision of scholarship [PoS], Donations/Grant [D/G], Construction of Road $[\mathrm{CoR}]$ as shown in the model.

$$
\begin{gathered}
\text { SW }=\mathrm{F}(\text { EOR }) \\
\mathrm{SW}=\mathrm{a}_{0}+\mathrm{a}_{1} \text { EOR }+\mathrm{e} \\
\mathrm{SW}=\mathrm{a}_{0}+\mathrm{a}_{1} \mathrm{CF}+\mathrm{a}_{2} \mathrm{IPB}+\mathrm{a}_{3} \mathrm{ESPT}+\mathrm{a}_{4} \mathrm{PoS}+\mathrm{a}_{5} \mathrm{D} / \mathrm{G}+\mathrm{a}_{6} \mathrm{CoR}+\mathrm{e}
\end{gathered}
$$

$\mathrm{EOR}=$ Environmental Operation Review

SW $=$ Stakeholders' wealth

$\mathrm{CF}=$ Charges $\&$ forfeits

IPB = Interested parties' backing

ESPT $=$ Environmental safeguarding price tag

$\mathrm{PoS}=$ Provision of scholarship

$\mathrm{D} / \mathrm{G}=$ Donations/Grant

$\mathrm{CoR}=$ Construction of Road

$\mathrm{e}=$ Error term 


\section{Results}

Table 1. Regression outcome on the correlation between stakeholders' wealth and the indicators of environmental operations, stakeholders' wealth is the dependent variable

\begin{tabular}{lllll}
\hline Variable & $\begin{array}{l}\text { Predictable } \\
\text { factor }\end{array}$ & $\begin{array}{l}\text { Normal } \\
\text { Inaccuracy }\end{array}$ & $\begin{array}{l}\text { Value } \\
\text { Value }\end{array}$ \\
\hline Stable & 86.036 & 10.236 & 8.406 & 000 \\
\hline Charges \& forfeits & 0.557 & 0.237 & 3.543 & 0.012 \\
\hline Interested parties' backing & 1.842 & 0.337 & 6.565 & 0.000 \\
\hline Environmental safeguarding price tag & 0.227 & 0.129 & 2.781 & 0.013 \\
\hline Provision of scholarship & 2.551 & 1.023 & 3.417 & 0.001 \\
\hline Donations/Grant & 3.341 & 0.122 & 6.423 & 0.000 \\
\hline Construction of road & 3.243 & 1.002 & 4.324 & 0.012 \\
\hline R- Square & 0.875 & & & \\
\hline Adjusted R-square & 0.805 & & & \\
\hline F-statistic & 11.781 & & & \\
\hline Durbin Watson & 2.062 & & & \\
\hline
\end{tabular}

Source: Authors

\subsection{Test of Hypotheses}

$$
\begin{array}{r}
\mathrm{SW}=86.036+0.557 \mathrm{CF}+1.842 \mathrm{IPB}+0.227 \mathrm{ESPt}+2.551 \mathrm{PoS}+3.341 \mathrm{D} / \mathrm{G}+3.243 \mathrm{CoR} \\
\text { T-value }(8.406)(3.543)(6.565)(2.781)(3.417)(6.423)(4.324)
\end{array}
$$

\subsubsection{Hypothesis One}

Ho: Environmental safeguarding price tag does not substantially influence the stakeholders' wealth of extracting firms.

$\mathrm{H}_{1}$ : Environmental safeguarding price tag substantially influences the stakeholders' wealth of extracting firms.

By means of the t- value in place of the assessment benchmark the calculated t-value is 2.781 whereas the bench value at gradations of freewill n-2 (i.e. 1.788). This suggests that the calculated worth is more than the bench value, the unsound proposition is disallowed and the unconventional conventional, connoting that there is a substantial relationship between Environmental safeguarding price tag and stakeholders' wealth of extracting firms.

\subsubsection{Hypothesis Two}

Ho: Stakeholders' wealth of extracting firms is not substantially affected by charges and forfeits.

$\mathrm{H}_{1}$ : Shareholders' wealth of extracting firms are substantially affected by charges and forfeits.

With the t-value on the outcome shown above, the calculated t-value is 3.543 while the table value at degrees of freedom n-2 (i.e. 1.788). This denotes that the calculated value is larger than the bench value, the null proposition is overruled and the other recognized, indicating that shareholders' wealth of extracting firms is substantially affected by charges and forfeits.

\subsubsection{Hypothesis Three}

Ho: Interested parties' backing does not significantly affect stakeholders' wealth of extracting firms.

$\mathrm{H}_{1}$ : Interested parties' backing does significantly affect shareholders' wealth of extracting firms.

Based on the t-value, the figured t-value is 6.565 while the table value at degrees of freedom n-2 (i.e. 1.788). This implies that the computed value is greater than the table value, the null hypothesis is disallowed and the alternative recognized, showing that interested parties' backing does significantly affect stakeholders' wealth of extracting firms. Also, considering the latter part of table 1 above, it could be strongly deduced that the three social variables, 
provision of scholarship donations and construction of the road to the host community by the extractive firms can be used to predict the interested party wealth as their respective T-value was statistically important.

\subsection{Discussion of Findings}

For the study to appropriately and accurately situate stakeholders' wealth and wealth maximization objective as the reliant adjustable as well as determine its connection by means of selected major cost-effective, capital budgeting processes and financial adaptable particularly the ones reflected as the key determining the factor of ecological and conservational actions and undertakings, consequently regression analysis was carried out to estimate the magnitude of the influence of the research independent adaptable in this case, charges \& forfeits [CF], interested parties' backing [IPB], environmental safeguarding price tag [ESPt], provision of scholarship [PoS], donations/grant [D/G] and construction of road $[\mathrm{CoR}]$. The experiential and practical outcomes discovered that: The measurement of charges \& forfeits is optimistic. This suggests that an upsurge in charges \& forfeits will increase stakeholders' wealth. The factor of interested parties' backing is progressive and affirmative, indicating that there be existent an affirmative connection amongst interested parties' backing besides stakeholders' wealth in extractive firms and this is supported by the research result submitted by Eyre (1982); Uwah and Asuquo (2016).

The assessed and validated measurement of the environmental safeguarding price tag is affirmative. This demonstrates an encouraging affiliation concerning environmental safeguarding price tag and stakeholders' wealth making reference to extractive firms in Nigeria. This submission is supported by the conservational durability principle and thereby being an indicator of the information that stakeholders' wealth/net asset is becoming conceivable from the perspective of environmental safeguarding price tag and in conformity with the outcome of the investigation carried out by Spiceland, Sepe, and Tomassini (2004); Asuquo, Dan and Effiong (2020). The pragmatic upshots revealed that: The dimension of the provision of the scholarship is positive. This proposes that an increase in the provision of the scholarship will intensify stakeholders' wealth. The influence of donations/grant is favorable, demonstrating that there is an assenting linking between donations/grant besides stakeholders' wealth taking evidence from extractive firms in investigated in Nigeria. The impact of the construction of the road in the host community is auspicious and propitious, establishing that there is a positive and harmonizing linking between constructions of the road in the host community and stakeholders' wealth captivating substantiation from extractive firms in explored in Nigeria. The value of Durbin Watson statistic clearly justified that there is no autocorrelation amongst the independent variables in the model.

\section{Conclusion}

Established on experiential as well as non-experiential investigation and deductions of environmental operation review and stakeholders' wealth of extracting firms, it was resolved and deduced that as the extracting firms in Nigeria wield influence on the environs within which they operate and carry out their numerous events and dealings, there are positive/negative externalities of their activities on the shareholders' wealth of extracting companies with supporting facts from extracting firms in Nigeria. All over again, conservational and ecological wealth is being exhausted or worn-out after many years due to the activities of the extracting corporations in the environs/ecosystem.

Exclusively, the actions and deeds of extracting firms in Nigeria wield severe adverse effects on the environs/ecosystem by way of toxic waste, extinction of forest, lubricant emission, gas flaring, to mention a few of these. Consequently, environmental/ecological conservation and improvement is greatly hindered by taking a clue and trace from Nigeria (Okon, 2018). The study, therefore, suggested that Nigerian extracting corporations ought to display statistics on conservational outlay, ecological fee expended in the earnings justification, and particulars in the proceedings of the financial statement. To heighten the efficacy of the guiding principle, a distinct explanation ought to be upheld for conservational outlays. This will safeguard quantifying in addition to the recording of conservational/ecological outlays as well as the ecological enactment of each corporation and/or the entire extracting industries.

As submitted by Asuquo (2012a), and Asuquo, Dan and Effiong (2020) incalculable discarded components as well as social leftover are produced by societal undertakings into our surroundings and normal environments. The happening is characterized as ecological contamination which has been demarcated as an unsolicited modification in natural, somatic or biochemical structures of the land, air or water which may be detrimental to the lives of humans and other living things, living environments, cultural assets, and industrial process or led to raw material wastes. Impurities' access conveyed as ecosystem turbulences which occasioned acute on a sequence of adversarial responses often very intricate in normal environments. The derelictions of the environments can negate too many glitches subject to the system and flora of the environment that is compressed by the nature of contaminants carrying the problem as supported by the study can be recognized and controlled by environmental operations review (Asuquo, Dan \& 
Effiong, 2020).

\section{Future Scope}

The paper though was written with particular reference to environmental operations review and stakeholders' wealth of extracting firms in Nigeria, applied both local and global standards in evaluating environmental issues both qualitatively and quantitatively. Nevertheless, we expect that more comparative studies would be carried out on qualitative issues as recommended by global initiatives on environmental/ecological habitat impact assessment.

\section{Acknowledgments}

We sincerely acknowledge the following persons or group of persons for their massive assistance and backing towards the effective conclusion of the study and writing of its report: Staff of Nigeria Environmental Protection Agencies; New Map Calabar, CBN, Bureau of Statistics, to mention a few.

\section{Conflict of interest}

The authors say publicly that there is no conflict of interest.

\section{References}

Anijah, O. (2001). Fundamentals of environmental education and management. University of Calabar Press, Calabar, Nigeria.

Asuquo, A. I. (2012a). Environmental friendly policies and their financial effects on corporate performance of selected oil and gas companies in Niger Delta Region of Nigeria. American International Journal of Contemporary Research: Centre for Promoting Ideas, 2(1), 168-173.

Asuquo, A. I. (2012b). Empirical analysis of the impact of information technology on forensic accounting practice in Cross River State-Nigeria. International Journal of Scientific and Technology Research, 1(7), 25-33.

Asuquo, A. I. (2013). Analysis of financial accounting standards and their effects on financial reporting and practices of modern business organizations in Nigeria. European Journal of Business and Management, 5(4), 60-68.

Asuquo, A. I., Dan, N. O., \& Effiong, G. T. (2020). Effect of eco-friendly costs on net revenue of cement producing firms. International Journal of Scientific and Technology Research, 9(9), 235-240.

Awasthi, A. K. (2009). Social Choice and individual values. Yale University Press, Yale.

Babbie, X. K. (1990). The practice of social responsibility (4th ed.). Ca Wads Worth Publishing Company, Belmont.

Backman, M. P. L. (2003). Social responsibility and accountability. NY G-Press, New York.

Brian, J. T. (1999). The effects of environmental regulation on business location and performance. The United States' Growth Change, 19(3), 22-24. https://doi.org/10.1111/j.1468-2257.1988.tb00473.x

Cohen, A. R., Fink, S. L., Gadon, H., \& Willits, R. D. (2001). Effective behaviour in organizations: Cases, concepts, and student experience (7th ed.). United States of America.

Davies, N., \& Okorite, L. (2014). Corporate social responsibility accounting: A wake-up call to The Nigerian Accountant. The Nigerian Accountant May/June (2014).

Dawkins, W. E. (2003). Cost benefit analysis and project evaluation, a comparison of alternative approaches. Journal of Public Economics, 22(5), 623-302.

Digo, I. B. (2004). Advanced Accounting theory. Eddy Publications, Zaria.

Edwards, O. B. (2005). The marginal effects of environmental science. Ultimate Index Book Publishers, Calabar, Nigeria.

Effiong, S. A., \& Asuquo, A. I. (2010). Environmental accounting and environmental cost reporting: Implications and prospects for business survival. African Journal of Management and Administration, 3(4), 144-147.

Effiong, S. A., Udoayang, J. O., \& Asuquo, A. I. (2011). Correlational and Differential influence of historical cost and current cost profits on the operating capabilities of the firm. International Journal of Financial Research, 2(1), 64-70. https://doi.org/10.5430/ijfr.v2n1p64

Eyre, E. C. (1982). Mastering basic management, Macmillan Master Series. Macmillan Press Ltd., Britain.

Francis, I. A. (2019). Environmental issues and management in Nigeria development. Evans Brothers Publishers: Nigeria.

Friedman, H. J. (1980). Does business have social responsibility?. Bank administration, Harper and Row Ltd., New York. 
Gilpin, A. (1995). Environmental impact assessment. Cambridge University Press, Cambridge.

Gray, W. B. (2003). Pollution abatement costs, regulation, and plant-level Productivity. Washington: Centre for Economic Studies, US Department of Commerce, 20-21.

Greenwood, W. P. (1999). Model comparison of the costs of reducing. Pitman, Great Britain, 19.

Harrington, W. R. (2000). The cost of air pollution abatement. Applied Economic Journal, 29(5), 759-774. https://doi.org/10.1080/000368497326688

Hodges, L. (1973). Environmental pollution (p. 331). Holt Rinehart and Winston Inc., New York.

Hohmeyer, T. B. (1993). Environmental accounting: Its role in regulated utilities. Retrieved September 27, 2009, from Http://www.financereg.com/cacc/utilities.htm

International Conservation Union [IUC]. (2000). Washington D.C. Retrieved from www.icun:org/places/US

John, B. O. (2001). The oil industry, environment health and sustainable development in Nigeria. African Journal of Environmental Studies, 2(2), 18-14.

Kontsoviannis, A. (2003). Modern microeconomics (2nd ed.). Macmillan Press Ltd., London.

Munasinghe, M. (1993). The economist approach to sustainable development, finance and development. Quarterly Publication of the IMF and the World Bank Dec., 30(4), 14-14.

Murphy, L. (2003). Environmental resources management and assessment for technological advancement. African Journal of Environmental Studies, 2(2).

Ojile, F. J. (1998). Introduction to environmental protection management. Safe Publishers, Lagos.

Okon, E. E. (2018). Legal framework of environmental impact assessment in Nigeria: The poor state of Compliance. Unpublished Workshop Paper, Calabar, Nigeria.

Olugbile, A. (1987). Environmental consideration is health in environmental policies in Nigeria. Bulletin of Science Association of Nigeria, 3(2).

Prestone, L. T. (1992). Responding to the development challenge, finance and development. The World Bank, 29(2), 5.

Raw, J. E., \& Jackson, T. T. (2006). Pollution abatement and control expenditures. Survey of Current Business in Nigeria, 24(5), 36-41.

Repetto, R. (1989). Economic Incentives for sustainable production. In G. Schramm, \& J. Worfood (Eds.), Environmental management and economic development by World Bank. The John Hopkins University Press, Baltimore.

Rilwani, M. L., \& Aziegbe, F. L. (2001). Environmental impact assessment and Nigerian development: A spatial perspective. Africa Journal of Environmental Studies, 2(2), 141-145.

Sada, S. P. (1999). Current issues in Environmental Management. Evans Brothers, Ibadan.

Smith, L. M. (2003). Accounting guidelines for environmental issues. Retrieved from www.environissues.org

Spiceland, J. D., Sepe, J. F., \& Tomassini, L. A. (2004). Intermediate accounting (3rd ed.). Irwin McGraw Hill Company Inc., New York.

Torstein, E. U. (2006). Environmental and natural resources economics. Ashford Colour Press, London.

Uwah, U. E., \& Asuquo, A. I. (2016). Capital budgeting processes and wealth maximization objectives: Implications for firms in Nigeria. Research Journal of Finance and Accounting, 7(10), 73-85.

Welford, R. (1995). Environmental strategy and sustainable development. The corporate challenge of the 21st century.

Wright, C. J., \& Noe, B. F. (2006). The Theory of environment and planning. Prentice Hall, India.

\section{Copyrights}

Copyright for this article is retained by the author(s), with first publication rights granted to the journal.

This is an open-access article distributed under the terms and conditions of the Creative Commons Attribution license (http://creativecommons.org/licenses/by/4.0/). 